\title{
Cation-dependent photochromic properties of novel ditopic receptors*
}

\author{
Olga A. Fedorova ${ }^{\ddagger}$, Y. V. Fedorov, E. N. Andrjukhina, S. P. Gromov, \\ and M. V. Alfimov \\ Photochemistry Center of Russian Academy of Sciences, Novatorov str., 7a, \\ Moscow, 119421, Russia
}

\begin{abstract}
Novel crown-containing 2-styrylbenzothiazoles were prepared to obtain optical ditopic receptors that can bind alkaline-earth metal cations by a crown ether fragment and could serve as host for the heavy metal cations and proton owing to the presence of the heterocyclic part. Photochemical transformations of the ditopic receptors depend on the type of metal cations present in solution. They include trans-cis-isomerization, [2+2]-cycloaddition, and electrocyclic reaction.
\end{abstract}

\section{INTRODUCTION}

The development of organic photochemistry has produced a number of new and useful reactions; some of them have found practical applications. The photochemical behavior of organic compounds seems to be well understood [1,2]. In contrast, the photochemistry of metal complexes is just developing; we can expect new and promising types of reactions in organometallic and inorganic chemistry.

One of the widely known classes of photochromic molecules is the stilbene-like molecule [3]. Introducing a crown ether moiety into the stilbene-like molecules gives substances that respond optically to the presence of metal cations or amines in solutions. Otherwise, we can expect that the complex formation can influence the photochemical behavior of the stilbene-like molecules $[4,5]$.

\section{RESULTS AND DISCUSSION}

To determine how the complex formation can be used for the control of the photochemistry of hetarylphenylethenes with ionophore fragments, we synthesized and investigated the crown-containing 2-styrylbenzothiazoles (CSB) 1, 2, 3 and their complexes.
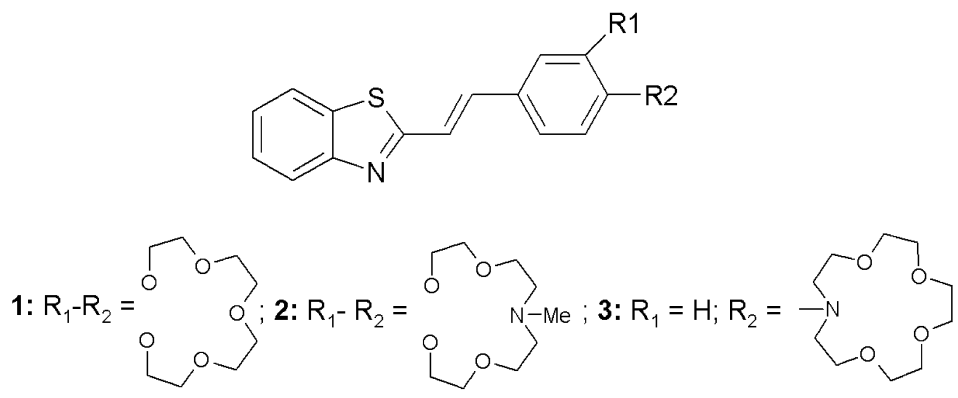

\footnotetext{
* Lecture presented at the XIX ${ }^{\text {th }}$ IUPAC Symposium on Photochemistry, Budapest, Hungary, 14-19 July 2002. Other presentations are published in this issue, pp. 999-1090.

ॠCorresponding author
} 


\section{Synthesis}

We devised different methods to prepare CSB 1 containing 15-crown-5 ether moiety (Scheme 1). 2-Methylbenzothiazole 4 and its phosphonium salt $\mathbf{6}$ were condensed with formyl derivatives of benzo15-crown-5 ether 5 in the presence of equamolar amounts of NaOMe in DMSO at ambient temperature for $24 \mathrm{~h}$ to form 1 with $53 \%(\operatorname{method} \mathrm{A})$ and $63 \%$ yields (method B) (Scheme 1) [6]. Heating the reactants 4 and 5 with concentrated $\mathrm{HCl}$ at $130{ }^{\circ} \mathrm{C}$ for $3 \mathrm{~h}$ results in compound 1 with yield $23 \%$, and some resinification occurs in the course of the process (method C, Scheme 1). The dye 8 [7] produces the resulting product 1 with $47 \%$ yield by heating with $\mathrm{PPh}_{3}$ (method E, Scheme 1). The condensation of malonic acid with 5 results in the formation of known-in-literature cinnamic acid $\mathbf{7}$ containing crown15-ether-5 fragment [8] that can react with $o$-aminophenole in benzene to form 1 with $16 \%$ yield (method D, Scheme 1). Among the studied reactions, one-step method A seems to be simpler with quite good yield of $\mathbf{1}$. The yield of $\mathbf{1}$ in methods $\mathrm{C}$ and $\mathrm{D}$ is low, whereas, the synthetic procedure in methods $\mathrm{B}$ and $\mathrm{E}$ is multisteps. applied.

Compound $\mathbf{2}$ was prepared by using method $\mathrm{A}$, whereas, to obtain the compound $\mathbf{3}$, method $\mathrm{C}$ was

Structural identification of 1-3 in solution was based on their ${ }^{1} \mathrm{H}$ NMR spectra. Assignment of $E$ configuration was on the basis of the spin-spin coupling constant for the olefinic protons, ${ }^{3} J_{\text {trans }}=15.6 \mathrm{~Hz}$.

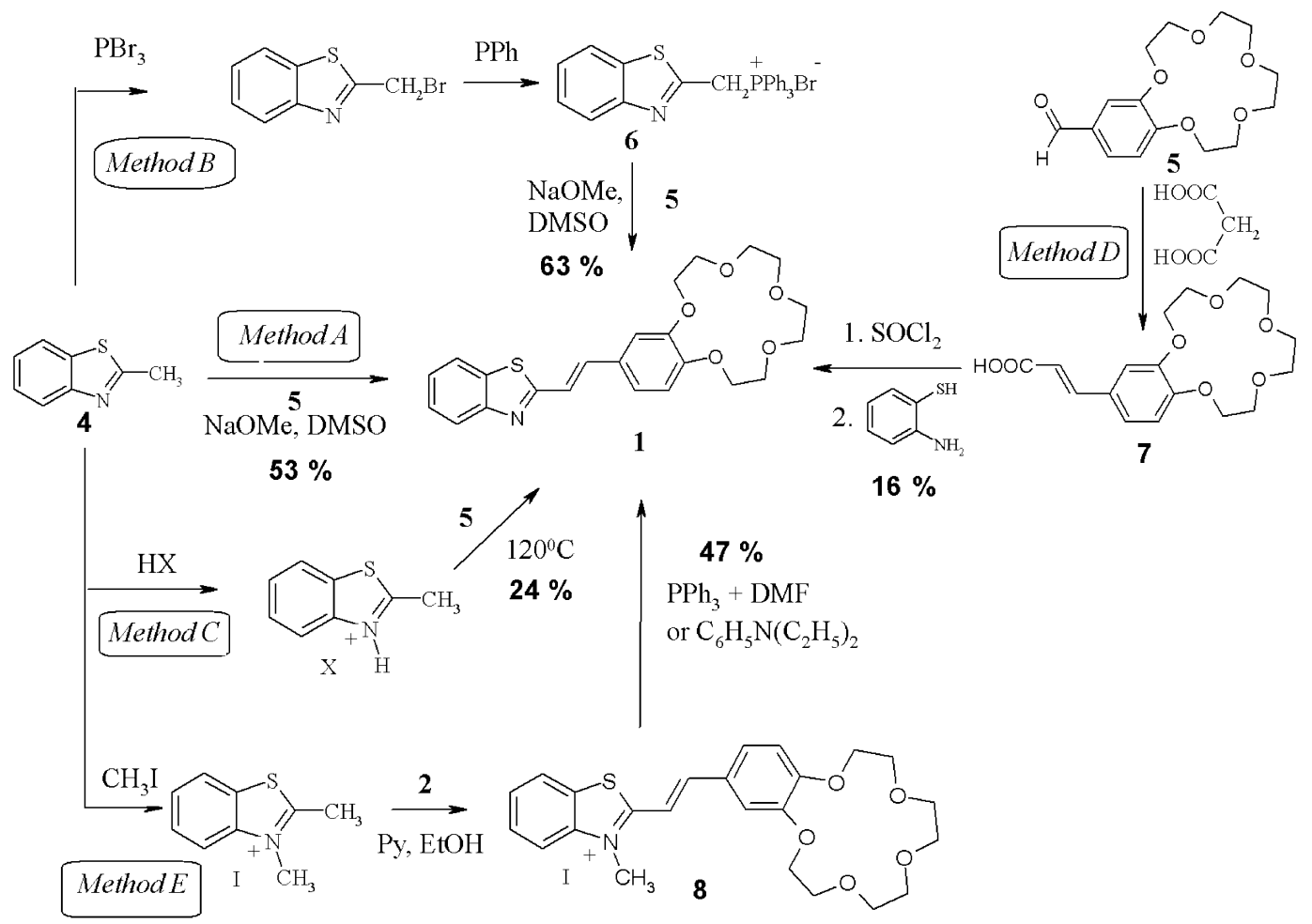

Scheme 1 


\section{Complex formation}

We assumed that it could be possible to use the crown ether 2-styrylbenzothiazole to obtain the optical ditopic receptor, which can bind alkaline-earth metal cations by crown ether fragment and would be a host for the heavy metal cations and proton owing to the presence of heterocyclic part.

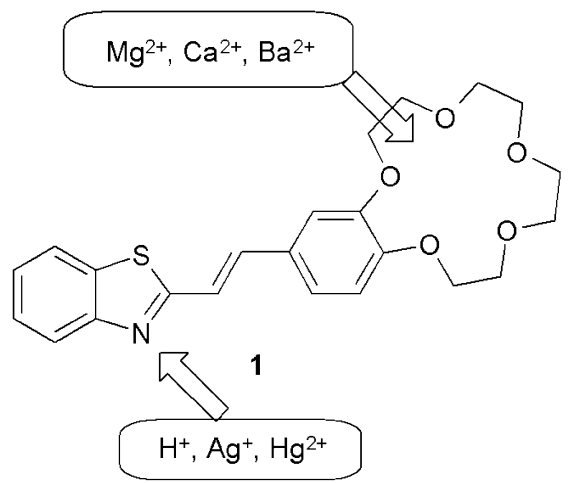

The $E$-isomers of CSB 1-3 exhibit strong absorption and fluorescence emission in the visible region (Table 1). The addition of metal cations to solution of CSB in MeCN resulted in change of position of the long wavelength absorption band and of the fluorescence band, which are evidently due to formation of complexes (Scheme 2).

Table 1 Spectral luminescence characteristics of CSB 1-3 and their complexes with the $\mathrm{Mg}^{2+}, \mathrm{Ca}^{2+}$, and $\mathrm{Ba}^{2+}$ cations in $\mathrm{MeCN}$.

\begin{tabular}{|c|c|c|c|c|}
\hline \multirow[t]{2}{*}{ Compound } & \multicolumn{2}{|c|}{$\begin{array}{c}\lambda_{\max } \mathrm{abs} / \mathrm{nm}, \\
\left(\varepsilon_{\max } \cdot 10^{-4} / \mathrm{L} \cdot \mathrm{mol}^{-1} \mathrm{~cm}^{-1}\right)^{\mathrm{a}}\end{array}$} & \multirow[t]{2}{*}{$\lambda_{\max }^{\mathrm{fl}} / \mathrm{nm}^{\mathrm{b}}$} & \multirow[t]{2}{*}{$\varphi_{\mathrm{fl}}^{\mathrm{c}}$} \\
\hline & $E$-isomer & Z-isomer & & \\
\hline $\mathbf{1}$ & $358(3.3)$ & $350(1.04)$ & 452 & 0.0135 \\
\hline 2 & 357 (3.3) & 349 (1.07) & 448 & 0.014 \\
\hline 3 & 399 (4.9) & $399(1.98)$ & 505 & 0.037 \\
\hline $1 \cdot \mathrm{Ca}^{2+}$ & $346(3.23)$ & $333(1.2)$ & 415 & 0.018 \\
\hline $2 \cdot \mathrm{Ca}^{2+}$ & $346(3.25)$ & $330(1.2)$ & 433 & 0.015 \\
\hline $3 \cdot \mathrm{Ca}^{2+}$ & $347(4.01)$ & $316(1.5)$ & 492 & 0.025 \\
\hline $\mathbf{1} \cdot \mathrm{Mg}^{2+}$ & $346(3.23)$ & & 408 & 0.02 \\
\hline $2 \cdot \mathrm{Mg}^{2+}$ & $352(3.24)$ & & 439 & 0.013 \\
\hline $3 \cdot \mathrm{Mg}^{2+}$ & $346(4.08)$ & & 489 & 0.023 \\
\hline$(1)_{2} \cdot \mathbf{B a}^{2+}$ & 345 (3.24) & & 446 & 0.037 \\
\hline $\mathbf{2} \cdot \mathbf{B a}^{2+}$ & 349 (3.21) & & 443 & 0.013 \\
\hline $3 \cdot \mathbf{B a}^{2+}$ & $357(4.12)$ & & 492 & 0.024 \\
\hline
\end{tabular}

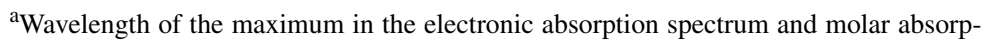
tion coefficient (in parentheses).

${ }^{\mathrm{b}}$ Wavelength of the maximum in the fluorescence spectrum.

${ }^{c}$ Fluorescence quantum yield in air-saturated acetonitrile at $20 \pm 1{ }^{\circ} \mathrm{C}$ relative to fluorescein in $0.01 \mathrm{M} \mathrm{NaOH}$ in water $\left(\varphi_{\mathrm{f}}=0.92\right)$ with excitation at $365 \mathrm{~nm}$. 


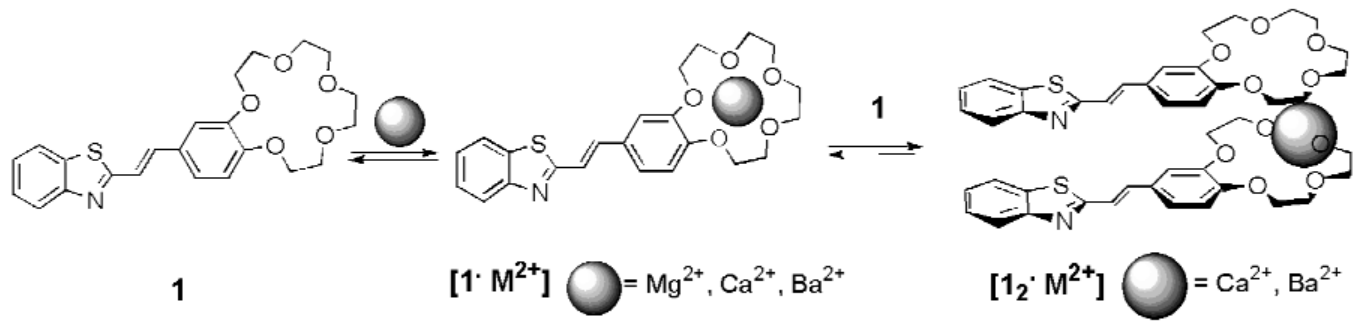

Scheme 2

The fluorescence quantum yields of free CSB 1 and $\mathbf{2}$ (see Table 2) are identical. The $\mathrm{N}$ atom in the azacrown ether fragment of CSB 3 is a stronger electron donor than the $\mathrm{O}$ atom in the benzocrown ether macrocycle of CSB $\mathbf{1}$ or $\mathbf{2}$, due to which the fluorescence quantum yield of CSB $\mathbf{3}$ is more than twice as large.

Table 2 Stability constants of the complexes of CSB 1-3 with the $\mathrm{Mg}^{2+}, \mathrm{Ca}^{2+}, \mathrm{Ba}^{2+}$, and $\mathrm{Hg}^{2+}$ cations in $\mathrm{MeCN}$ at $293 \mathrm{~K}$.

\begin{tabular}{lccccccc}
\hline CSB & \multicolumn{5}{c}{$\lg K_{11}$} & \multicolumn{3}{c}{$\lg K_{21}$} & $\lg K_{12}$ \\
\cline { 2 - 7 } & $\mathrm{Mg}^{2+}$ & $\mathrm{Ca}^{2+}$ & $\mathrm{Ba}^{2+}$ & $\mathrm{Hg}^{2+}$ & $\mathrm{Ca}^{2+}$ & $\mathrm{Ba}^{2+}$ & $\mathrm{Hg}^{2+}$ \\
\hline $\mathbf{1}$ & $5.5 \pm 0.1$ & $5.6 \pm 0.1$ & $4.74 \pm 0.05$ & $5.6 \pm 0.1$ & $10.3 \pm 0.1$ & $10.76 \pm 0.04$ & $9.4 \pm 0.2$ \\
$\mathbf{2}$ & $5.4 \pm 0.1$ & $4.9 \pm 0.1$ & $5.1 \pm 0.1$ & & & & \\
$\mathbf{3}$ & $2.35 \pm 0.04$ & $3.6 \pm 0.04$ & $3.1 \pm 0.04$ & & & & \\
cis-3 & & $3.7 \pm 0.04$ & & & & & \\
\hline
\end{tabular}

Complex formation of CSB 1-3 with alkaline-earth metals and mercury(II) cations was studied by spectrophotometric titration $[9,10]$. The ratios of CSB 1-3 to $\mathrm{Mg}^{2+}, \mathrm{Ca}^{2+}, \mathrm{Ba}^{2+}$, or $^{2+}$ cations were varied by adding aliquots of solutions containing known concentrations of CSB 1-3 and corresponding metal cations to solutions of CSB 1-3 alone of the same concentrations. The absorption spectrum of each solution was recorded, and the stability constants of the complexes were determined using the «Hyperquad» program [11]. The complexation model involves the following equilibria:

(1) $\mathrm{L}+\mathrm{M}=\mathrm{LM}, \quad K_{11}=[\mathrm{LM}] /([\mathrm{L}][\mathrm{M}])$,

(2) $2 \mathrm{~L}+\mathrm{M}=\mathrm{L}_{2} \mathrm{M}, \quad K_{21}=\left[\mathrm{L}_{2} \mathrm{M}\right] /\left([\mathrm{L}]^{2}[\mathrm{M}]\right)$,

(3) $\mathrm{L}+2 \mathrm{M}=\mathrm{LM}_{2}, \quad K_{12}=\left[\mathrm{LM}_{2}\right] /\left([\mathrm{L}][\mathrm{M}]^{2}\right)$,

where L is CSB 1, 2, or 3, M is metal cations, $K_{11}, K_{21}$, and $K_{12}$ are the complex stability constants.

The stability constants of CSB $\mathbf{1}$ and $\mathbf{2}$ with alkaline-earth metals (see Table 2) are close and higher than the corresponding constants for CSB 3. Since the participation of the $\mathrm{N}$ atom of the crown ether cycle in the formation of the chromophoric system of dye $\mathbf{3}$ is substantial, this restricts the possibility of its participation in complex formation.

For the complex formation of CSB 2 with alkaline-earth metal cations, the fluorescence quantum yield remains almost unchanged. This indicates an insignificant participation of the $\mathrm{O}$ atom involved in the conjugated system of the dye in complex formation. Minor changes in the absorption spectra accompanying complex formation confirm this conclusion. Probably, the $\mathrm{N}$ atom in the macrocycle of CSB 2, owing to its high electron-donating ability, can efficiently bind to the metal cation, substantially neutralizing its positive charge and decreasing the influence on the chromophoric system of the dye.

In the case of CSB 1 complex formation with the $\mathrm{Ca}^{2+}$ and $\mathrm{Mg}^{2+}$ cations, fluorescence enhancement is observed. This phenomenon can be related to the fact that the conformational mobility of the 
macrocycle decreases for complex formation at the crown ether fragment, which decreases the rate constant of nonradiative deactivation and increases the fluorescence quantum yield.

The inverse ratio of the hypsochromic to hypsofluoric shifts is observed for CSB $\mathbf{3}$ complex formation. This distinction can be due to a change in the character of metal ion coordination and its position relative to the chromophoric system of the molecule, in particular, to the cleavage of the coordination bond of the metal with the $\mathrm{N}$ atom of the macrocycle (photoinduced metal recoordination). Such effects have earlier been observed for styryl dyes with similar structure [12,13].

Thus, the variation of the crown ether fragment structure in CSB can be used for controlling the optical response to complex formation.

The alkaline-earth metal cations with a large diameter $\left(\mathrm{Sr}^{2+}, \mathrm{Ba}^{2+}\right)$ and benzo-15-crown-5 derivatives are characterized by the formation of the 2:1 sandwich-type complexes (Scheme 2). In the case of $\mathrm{Ba}^{2+}$, the sandwich complex formed possesses the highest stability. According to the NMR study of the sandwich complex $\left[\mathbf{1}_{2} \cdot \mathrm{Ba}^{2+}\right]$, molecules of dye are arranged in a "head-to-head" stacking in this complex. This conclusion is based on the upfield shifts of aromatic proton signals in the sandwich complex in comparison with the free ligand. The changes in NMR could be due to ring-current effects produced by the adjacent conjugated molecules. The downfield changes of proton signal positions of crown ether fragments point out the formation of complex with Ba cation through the macrocyclic moiety.

Addition of $\mathrm{HClO}_{4}$ to an acetonitrile solution of CSB 1 resulted in the formation of a perchlorate salt of 1 ( $\lg K_{11} 6.4 \pm 0.5$ ), whose long wavelength absorption band was red-shifted relative to the corresponding free ligand $\mathbf{1}$ (Scheme 3 ).

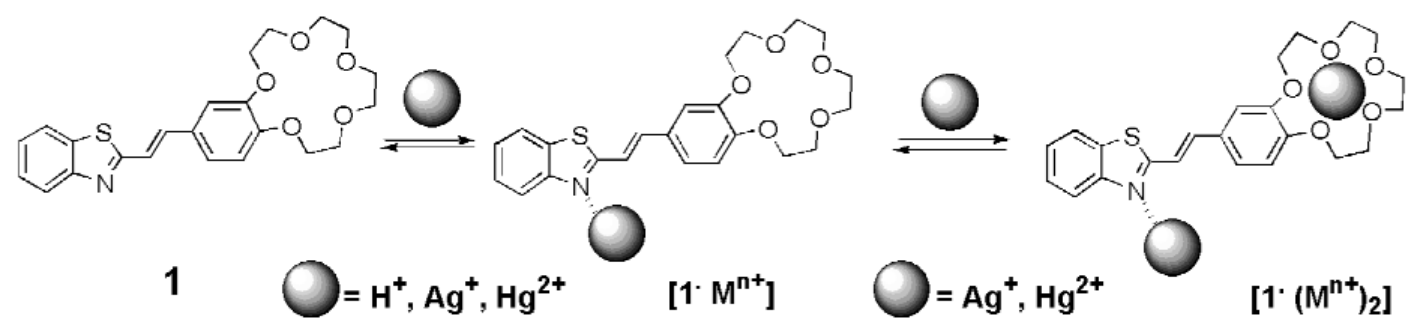

Scheme 3

Addition of $\mathrm{Hg}$ perchlorate to the acetonitrile solution of the dye $\mathbf{1}$ produced also a red-shift of the UV spectrum relative to the free ligand similarly to those observed in the case of the proton addition. The results of the spectrophotometric titration reveal the formation of two complexes (Scheme 3 ). At first, upon the addition of $\mathrm{Hg}\left(\mathrm{ClO}_{4}\right)_{2}$ to the dye solution, the bathochromic shift occurs, indicating the formation of complex $\left[\mathbf{1} \cdot \mathrm{Hg}^{2+}\right]$ through the heterocyclic part of the molecule. At higher $\mathrm{Hg}^{2+}$ concentration, the formation of $\left[\mathbf{1} \cdot\left(\mathrm{Hg}^{2+}\right)_{2}\right]$ complex is observed, its stability constant is indicated in Table 2. The formation of the $\left[\mathbf{1} \cdot\left(\mathrm{Hg}^{2+}\right)_{2}\right]$ complex is accompanied by a blue-shift of a long wavelength absorption band, which means that the second $\mathrm{Hg}^{2+}$ ion is bound to the crown ether moiety (Scheme 3 ).

Addition of $\mathrm{AgNO}_{3}$ to the dye $\mathbf{1}$ solution provokes too small changes in UV spectrum to allow the measurement of the stability constant or to determine the stoichiometry of the complex. But, we were able to find the experimental condition needed to prepare a Ag complex of dye 1, with a 2:1 stoichiometry $\left[\mathbf{1} \cdot\left(\mathrm{Ag}^{+}\right)_{2}\right]$ demonstrated by a crystallographic study. The frontal and side views and the atom-labeling scheme for $\left[\mathbf{1} \cdot\left(\mathrm{Ag}^{+}\right)_{2}\right]$ are shown in Fig. 1. The Ag cations are coordinated to both coordination positions of the dye, including the crown ether and the benzothiazole moieties. 


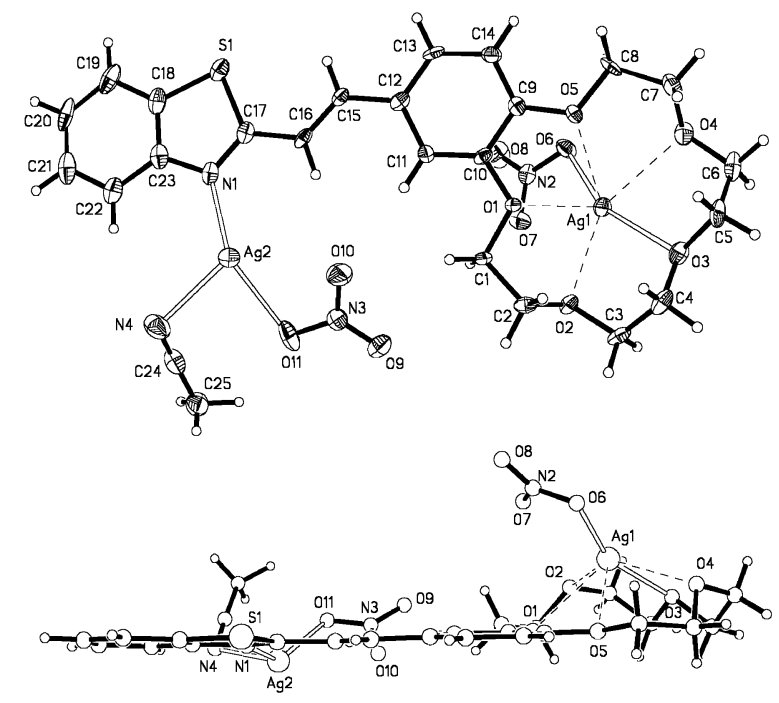

Fig. 1 Frontal (above) and side (below) projections of structure $\left[\mathbf{1} \cdot\left(\mathrm{Ag}^{+}\right)_{2}\right]$ with atom-labeling scheme. Thermal ellipsoids are drawn at the $50 \%$ probability level.

When solutions of CSB 1-3 or their complexes with $\mathrm{Mg}^{2+}$ in acetonitrile are irradiated with the light with $\lambda=405 \mathrm{~nm}$ (for $\mathbf{3}$ ) and with $\lambda=365 \mathrm{~nm}$ (for $\mathbf{1}$ and 2), absorption in the region of the longwave band decreases with the simultaneous increase in the absorption in the short-wave spectral region until the photostationary state is achieved. These spectral changes can be explained by reversible photochemical trans-cis-isomerization around the central $\mathrm{C}=\mathrm{C}$ double bond (Scheme 4). For CSB 1-3 the difference in the wavelengths of the absorption maxima for the trans-and cis-isomers is very low, and the $\varepsilon_{c} / \varepsilon_{t}$ ratio is rather high, which indicates an efficient conjugation in the $c i s$-form between the heterocyclic group and crown ether fragment [10]. It is most likely that in cis-1-3 molecules, these structural fragments and $\mathrm{C}=\mathrm{C}$ double bond are localized in the same plane, which provides a high efficiency of conjugation between them. The stability of the cis-isomers is very high: no dark isomerization was observed.

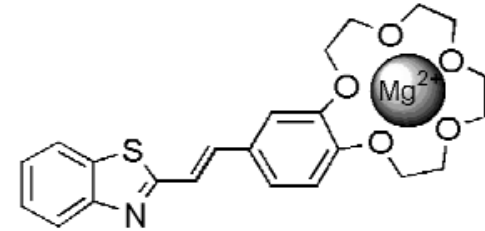

trans- $\left(1-\mathrm{Mg}^{2+}\right)$

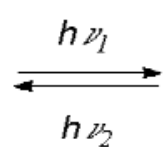

$h / 2$

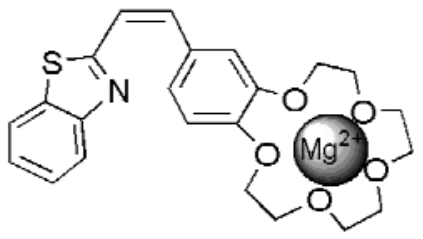

cis- $\left(1-\mathrm{Mg}^{2+}\right)$

\section{Scheme 4}

In the sandwich complex with $\mathrm{Ba}^{2+}$ cations, the mutual arrangements of 2-styrylbenzothiazole molecules is favorable for the occurring of the reaction of the photocycloaddition. Upon irradiation with blue light, 1 undergoes stereoselective [2+2]-photocycloaddition (PCA) to afford isomeric cyclobutane derivatives "trans+trans" (78\%) and "trans+cis" $(22 \%)$ with relatively high combined quantum yield (0.13) (Scheme 5). 


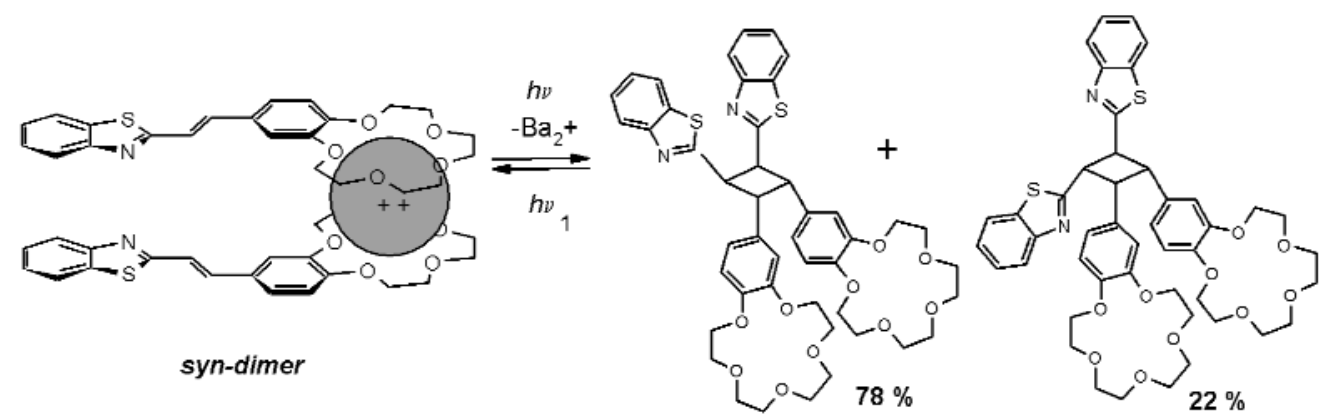

Scheme 5

Prolonged irradiation of the crown-containing CSB 1 in presence of $\mathrm{Hg}^{2+}$ or $\mathrm{Ag}^{+}$salts leads to the electrocyclic reaction followed by oxidation process producing of the novel cycloproduct, which can be considered as promising chromoionophore (Scheme 6). The reaction is a first example of the participation of $\mathrm{N}$ atom of heterocyclic residue in formation of cycle in the course of electrocyclic reaction. Also, it is an advanced photochemical method for the preparing of the novel class of optical sensors.
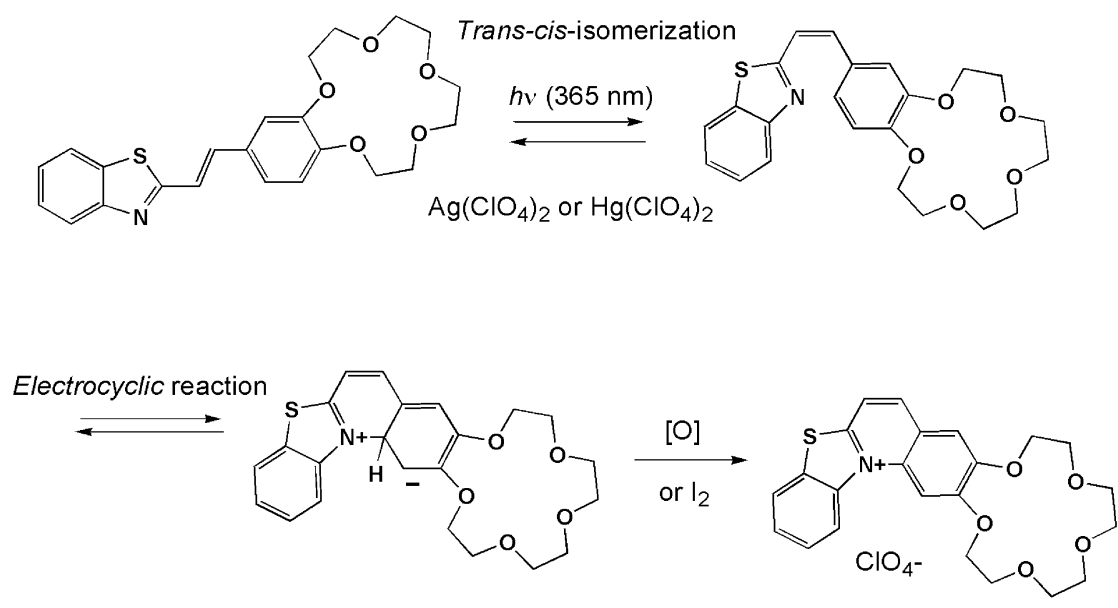

\section{Scheme 6}

Thus, the photochromism of the free ligand $\mathbf{1}$ is based on reversible reaction of trans-cis-isomerization. The photochromic behavior of the complexed crown-containing 2-styrylbenzothiazole depends on the metal cation types and includes the reversible reaction of trans-cis-isomerization, stereospecific reaction of [2+2]-photocycloaddition and electrocyclic reaction.

\section{ACKNOWLEDGMENTS}

The contribution of Profs. L. G. Kuzmina and J.-J. Aaron is gratefully acknowledged. This research was supported by CRDF Grant RC2-2344-MO-02 and RFBR Project No 02-03-33058. Thanks are also given to Prof. Rene Lapoyaude for fruitful discussions of the results and the support of this research. 


\section{REFERENCES}

1. H. Durr and H. Bouas-Laurent (Eds.). Photochromism: Molecules and Systems, Elsevier, Amsterdam (1990).

2. J. C. Crano and R. Guglielmetti (Eds.). Organic Photochromic and Thermochromic Compounds, Plenum Press, New York (1999).

3. A. Mishra, R. K. Behera, P. K. Behera, B. K. Mishra, G. B. Behera. Chem. Rev. 100, 1973-2011 (2000).

4. O. A. Fedorova and S. P. Gromov. In Targets in Heterocyclic Systems. Chemistry and Properties. 4, 205 (2001).

5. O. A. Fedorova, S. P. Gromov, M. V. Alfimov. Russ. Chem. Bull. 50, 1882 (2001).

6. O. A. Fedorova, E. N. Andrijkhina, A. V. Lindeman, S. S. Basok, T. Y. Bogashenko, S. P. Gromov. Russ. Chem. Bull. 51, 319 (2002).

7. S. P. Gromov, O. A. Fedorova, M. V. Fomina, M. V. Alfimov, Patent 2012574 RF (1994).

8. M. Shirai, T. Orikata, M. Tanaka. J. Polym. Sci.: Polym. Chem. Ed. 23, 463 (1985).

9. Yu. V. Fedorov, O. A. Fedorova, S. P. Gromov, E. N. Andrijkhina, M. V. Alfimov, J.-J. Aaron. New J. Chem. 27, 280-288 (2003).

10. Yu. V. Fedorov, O. A. Fedorova, S. P. Gromov, M. B. Bobrovskii, E. N. Andrijkhina, M. V. Alfimov. Russ. Chem. Bull. 51, 789 (2002).

11. P. Gans, A. Sabatini, A. Vacca. Talanta 43, 1739 (1996).

12. S. I. Druzhinin, M. V. Rusalov, B. M. Uzhinov, M. V. Alfimov, S. P. Gromov, O. A. Fedorova. Proc. Indian Acad. Sci. (Chem. Sci.) 107, 721 (1995).

13. S. P. Gromov, A. A. Golosov, O. A. Fedorova, D. E. Levin, M. V. Alfimov. Russ. Chem. Bull. 44, 124 (1995). 